\section{ENCYSTED VESICAL CALCULUS WITH PEDICLE}

\author{
A. A. BONDURANT, M.D. \\ CAIRO, ILL.
}

History.-The patient, Mrs. F. L. H., consulted me March 16, 1909, giving the following history. She had ceased to menstruate several years ago and had never been pregnant; she had a feeling of pressure and bladder irritation for at least fifteen years, a bearing down when ascending stairs, and a sensation like fire darting from side to side of the abdomen on the least exertion. She could not stoop over, as it made her feel as if a cord was drawn across the lower part of the abdomen. She had seen several physieians and had had treatment for uterine and bladder trouble. She had worn pessaries and had bladder irrigation among other remedies, which gave only temporary or partial relief at times. She was neurotic and discouraged.

Examination.-I found a very sensitive spot in the urethra just in front of the bladder. The patient had used irrigation so much that I first thought it traumatic from catheterization. The bladder was somewhat contracted and very tender to sound touch. I found what seemed to be a large rough stone encysted at inferior posterior part of bladder, dragging the wall of bladder down slightly to left. Both vaginal and rectal examination (digital) revealed what seemed to be a large stone in bladder. The sound would pass over and about the roughened body but could elicit no distinct click. I diagnosed large stone probably encysted and three other physicians confirmed my opinion.

Operation.--I advised operation and chose suprapubic in cision, which was done on March 22, 1909. I made an incision to admit the index-finger and found the supposed stone com pletely walled off from cavity of bladder, but bimanual manipulation proved it connected with posterior wall of bladder. I immediately closed the incision in the bladder completely by means of two rows of sutures; one reinforcing. I left a smal drain to the bladder wall, and next made an incision above into the peritoneal cavity which had not previously been opened and found the calculus attached to posterior wall of the bladder by means of a very short pedicle which was really an extension of the peritoneal coating of the bladder and completely enveloped the mass of hard tissue which was principally osseous with some fibrous or connective tissue. I had no trouble in ligating and removing it. I closed the wound completely. The specimen weighed 378.084 grains, and measured a little over 2 by $1 \frac{1 / 3}{3}$ inches.

Postoperative History.-Two small stones the size of small peas were passed by the urethra, May 13, 1909, seven weeks after operation. They may have been there or forming at the time of operation, but I failed to detect them after a very thorough search. The shock was not excessive and temper. ature was never high. A stitch abscess from the upper incision produced a chilly sensation and temperature of 103 about the seventh day, which was promptly relieved by opening the abseess. I kept catheter in the bladder nine days, irrigating with boracic acid solution once or twice daily. I decided to risk union of bladder, as I had had no leakage at any time and directed the introduction of catheter every three hours, or more frequently if the patient was distressed from accumu lation of urine. All went well until the end of the eleventh day from time of operation, when a slight quantity of urine came from first incision. Leakage continued more or less for two weeks, when bladder was distended even to moderate degree, after which progress was uninterrupted. Bladder symptoms gradually subsided until now, four months since operation, the patient has practically no trouble with it. The other distressing symptoms have disappeared and she looks and feels like a new person. This is certainly a rare specimen and, so far as I have been able to learn, the first with such an attachment.

The Reward of Industry.-The stairs that lead throneward start in low places. The world has owed most to its men of lowly birth. Let not the poor man murmur. To him belongs the future. Tle thrones of thought and of influence may be his if he is willing to climb up to them.-United Presbyterian.

\section{A FAMILY EPIDEMIC OF ACUTE TRICHINIASIS * \\ JOSE L. HIRSH, M.D. \\ Professor of. Pathology, University of Maryland BALTIMORE}

The house epidemic of trichiniasis which I wish to report first came under my observation on Feb. 7, 1909, and the history was later obtained.

The household consists of eight members, namely, a grandmother, mother, five adult children and a servant. On Jan. 31, 1909, the mother purchased in the market a variety of ham which is usually eaten raw. This was eaten by the five children; the grandmother, mother and servant did not partake of it. The disease was limited to the five children.

\section{REPORT OF CASES}

CASE 1.-Miss E., aged 23, was seen on February 7, seven days after eating the ham. Her previous history is practically negative. The present illness began the previous day, the chief complaint being indefinite pains all over the body and a decided edema of the eyelids. There was no nausea or vomiting or diarrhea. Tongue was coated; heart, lungs and abdominal organs were normal. Temperature was 100 , pulse 85; respirations 20. Patient was menstruating at this time, so no urinary examination was made until a week later, when the urine was normal.

On February 8, the edema about the eyelids increased, involved entire face and the soreness and stiffness about the muscles increased. Temperature was 101. The condition resembled very much the grippe, which was prevalent at this time and which $I$ took it to be. Blood examination showed 7,600 leucocytes. Widal reaction negative.

February 10: Patient complained of severe headache and considerable abdominal colic. The pains in the muscles of the neck and chest had become much aggravated, although at no time during the illness were there the exquisite pains which of ten accompany an acute myositis.

By February 15 the condition had remained practically the same, temperature varying from 99 to $104 \mathrm{~F}$. Blood examination gave the following results: red blood cells, $5,000,000$, leucocytes 8,000; hemoglobin 90 per cent. A differential count of leucocytes showed neutrophiles 55 per cent., small and large mononuclears and transitionals 11 per cent., eosinophiles 34 .

A leucocyte coint made on February 24 slowed 18,000 with an eosinophilia of 32.4 per cent.

The condition remained practically the same for the next week. The variations in the temperature were very great, now and then reaching normal in the morning and evening, to be followed the next day by a rise to $102-103 \mathrm{~F}$. The condition lasted three weeks; then the patient slowly convalesced.

CASE 2.-Mr. M. A., aged 28, on February 8, noted that his eyelids were somewhat swollen and that he had a tired feeling; he became exhausted on very slight exertion. He had not been feeling perfectly well for past three days. No nausea, vomiting or diarrhea was present. On February 10, the patient took to bed, with a picture of typical typhoid fever. At this time examination showed face anxious, severe headache, mild delirium, tongue dry, abdomen somewhat distended and decid. edly tender on pressure; muscles of back and extremities painful on motion and uncomfortable on pressure; thoracic and abdominal organs negative; temperature, 104; pulse, 110; respirations, 28. Leucocy te count was 7,000 ; Widal negative and urine normal.

The condition remained practically the same for two weeks, when all the symptoms began to subside. There was no intermission in the temperature curve, which varied from 100 to 105. At no time were the muscles very tender on pressure, but the slightest movement was painful. Leucocyte counts made at various intervals (table of blood examinations) showed a constant leucopenia, on one occasion dropping to 4,300 leucocytes per $\mathrm{mm}$. The eosinophilia varied from 21.6 to 38.7 per cent.

* Read before the Medical and Chirurgical Faculty of Marylard. 
CASE 3.-Mr. G., aged 34, seen February 8, gave the following history. On February 6 patient had a severe attack of abdominal cramps which he attributed to drinking a glass of very cold beer just before retiring; he felt fairly well the following day, but the cramps returned the morning of the day I saw him. At this time he complained of great lassitude and later in the day vomited.

The following day, February 9, he was unable to get out of bed on account of the soreness and stiffness about the muscles; there was a slight puffiness about the eyelids which increased toward night. Headache and restlessness became more marked. Temperature was 99.5, pulse 90, respirations 20 .

This was the mildest infection and ran its course in about three weeks. The blood examination in this case is of particular interest in that the eosinophilia was most pronounced, reaching on one occasion to 40.4 per cent, the highest of any in the series. Likewise the highest leucocyte count, 14,000, was noted in this case.

CASE 4.-Mrs. G., aged 27 , had the most severe infection and gave the most typical picture of the disease. On February 10, eight days after eating the ham, the first definite symptoms appeared. The patient complained of feeling tired and the eyelids were swollen. There was no nausea or vomiting; bowels were constipated. Temperature was 99 , pulse 80 .

On February 12 patient went to bed. She was now complaining of severe heajache, so intense as not to allow her to sleep day or night and requiring morphin to give relief. The following morning, vomiting began and was repeated at intervals of every few hours for the next two days. Physical examination at this time was negative as to heart, Iungs and abdominal organs. Temperature was 102.

On February 18 headache was still a prominent feature; there were very severe abdominal cramps. Eyelids were still edematous. Pressure on the scaleni muscles gave exquisite pain. The biceps and gastrocnemi were painful both on pressure and motion; the limbs felt comfortable when they became fixed in one position, but any change from this position was attended with pain; patient said that the legs felt as if they might be made of wax and were straightened or bent only with effort. Patient complained of a peculiar pain in the upper abdomen saying she could feel it move up and down with each breath; this was undoubtedly due to the involvement of the diaphragm.

On February 20 an intense urticaria appeared over the whole body. The temperature in this case was of an intermittent type. On February 20 and 21 the temperature was normal; on the $22 \mathrm{~d}$ and $23 \mathrm{~d}$ it rose to 103 . The respirations were constantly rapid, varying from 25 to 40 ; even with normal temperature the respiratory rate was as high as 30 , probably owing to the diaphragmatic involvement. The blood chart in this case is also of interest; at no time was there a leucocytosis, the leucocytic count varying from 6,300 to 8,000 . Likewise the eosinophilia was but of a comparative moderate degree varying from 14 to 36 per cent.

On February 27 the patient felt better and was able to sit up; the muscles still felt tender; there had been no nausea or vomiting for past few days. Temperature was normal.

Examinations of stools both by myself and Dr. Adler were negative for parasites.

CASE 5.-Mr. J. A., aged 21, was feeling well until February 11, when he began to complain of lassitude and pain in the legs, especially when going up the steps. Slight headache was present; no nausea, vomiting or diarrhea. Physical examina. tion at this time was negative.

When patient awoke on February 12 he noted a wellmarked puffiness of the eyelids. Pains in the muscles of the extremities increased. Pain was felt on motion or pressure, especially over the biceps and gastrocnemius. Temperature was 102 , pulse 100 , respirations 22 .

On February 15 the patient was suffering from severe headache and insomnia. Temperature was continuously high with no intermissions.

On February 18 leucocyte count was 6,800 , with 27 per cent. eosinophiles.

All these patients recovered, the duration of the attacks varying from three to six weeks.

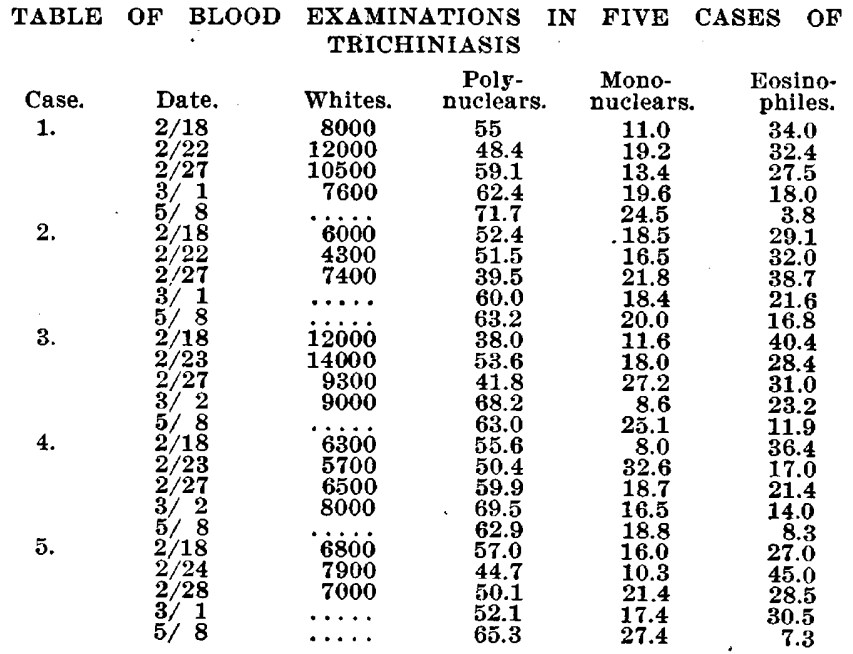

DISCUSSION OF CASES

An analysis of the symptoms as shown by this group of cases shows several points of interest.

The earliest symptoms showed themselves about the sixth to tenth day after the ingestion of the meatprobably at the time when the larvæ had fully devloped.

Edema of the eyelids was present in every case; in three of the patients it was the first symptom observed. This edema was of a character resembling that seen in Bright's disease. In two patients the entire face was puffy. No swellings were noted elsewhere.

Gastrointestinal symptoms were the following: Abdominal cramps were present in all; in two of a particularly severe type. Nausea and vomiting was noted in Cases 3 and 4 of a particularly aggravated type in the latter. Diarrhea was not present in any; to the contrary, constipation was troublesome.

Muscle pains were prominent symptoms. All complained of a general soreness over the entire body, and before taking to bed walking became difficult. When at rest in bed the limbs would become fairly comfortable when in a fixed position, but the least motion was associated with discomfort. In but one (Case 3) was the pain of an acute nature on pressure, and this was especially evident in the scaleni; an interesting observation in the same patient was the excursion of pain following the course of the diaphragm on deep expiratory and inspiratory efforts.

In two of the cases the temperature remained constantly high; in three there were intermissions, the temperature at times remaining normal for thirty-six hours and gradually rising to 103 . Chills were not present in any. Pulse corresponded to the temperature, as did also the respiration, except in Case 3 , in which the respiratory rate was constantly accelerated-probably associated with diaphragmatic involvement.

The urine was negative. The stools were negative for parasites. Urticaria was present in one case and was of an extremely aggravated variety, involving practically the whole body and lasting for three days.

\section{THE BLOOD}

The study of the blood in this disease by Brown ${ }^{1}$ has made trichiniasis one of the diseases of easy recognition. This one particular readily differentiates it from such diseases as typhoid fever, grippe and rheumatism. In Brown's original study of 3 cases, the chief change noted in the blood was a leucocytosis, in which the increase of the leucocytes occurred in the eosinophiles.

1. Brown, T. R. : Jour. Exper. Med., 1898, p. 315. 
The leucocytes varied in number from 8,000 to 30,000 per cubic mm. and the eosinophiles from 8 to 68 per cent., this eosinophilia corresponding to a decrease in the neutrophiles. This observation has been confirmed by Blumer and Neuman ${ }^{2}$ in an epidemic of 9 cases, by Cabot, $^{3}$ Kerr, ${ }^{4}$ Kinnicutt, ${ }^{5}$ Atkinson ${ }^{6}$ and others.

A study of the blood charts in my cases fails to show a constant leucocytosis; in only 2 of the 5 cases was there a leucocytosis, and that was of a moderate degree, in Case 1 rising to 18,000 and in Case 3 to 14,000 . In Cases 2 and 4 there was a decided leucopenia; in the former the leucocytes varied from 4,300 to 7,400 and in the latter from 5,700 to 8,000. In Case 5 leucocytes were normal- 6,800 to 7,900 .

The eosinophilia, however, was constant, and varied from 18 to 45 per cent. There was no relationship, however, between the severity of the infection and the extent of the eosinophilia; in Case 3, which was the mildest, the eosinophiles reached 40.4 per cent., while in Case 4, the most severe infection, 36.4 per cent. was the highest count noted.

As to duration of the eosinophilia, examination of the blood on May 10, three months after the onset, showed an eosinophilia of 3.8 per cent., 16.8 per cent., 11.9 per cent., 8.3 per cent. and 7.3 per cent., respectively.

In one of Brown's cases there was an eosinophilia of 34.7 per cent. five months after the patient's discharge. Stump's case showed 15 per cent. eosinophilia after four and a half months.

To my great regret, I was not permitted to remove a piece of muscle from these patients, so that the diagnosis must rest on the history of five members of a family of eight eating uncooked ham, and these five becoming ill; the symptoms and the blood changes.

\section{TREATMFNT}

If one sees the cases early enough a brisk purgation may prove of value; but it is difficult to see that this can be of much service when the worm has penetrated the mucosa-the time when the patient is apt to come under observation.

There is no specific for the destruction of the embryos, although hexamethylenamin has been advised with the idea that the liberated formaldehyd has some effect. Relief of muscle and abdominal pains with opiates and hypnotics to procure sleep is about all that can be done until Nature takes care of the invading parasite.

The muscle trichina (the immature or larval form of the parasite) is a worm about $1 \mathrm{~mm}$. in length, which lives in the muscles of the body. It is usually rolled into a spiral and lies in a capsule which occasionally contains lime salts. If a piece of muscle containing living trichinæ is taken into the stomach of the host-as when uncooked pork is eaten-the capsule is dissolved and the trichinæ are set free. In the intestinal canal they attain maturity in about three days, when copulation takes place.

On about the seventh day after the ingestion of the muscle trichinæ the birth of the embryo begins, a process which may last for weeks. It has been estimated that a single female trichina may bear from 1,000 to 1,300 young. The female worm penetrates the intestinal wall and, according to the observation of Zenker, the dissemination of the embryos to the muscle is by way of the lymph spaces and then into the blood-stream.

2. Biumer and Neuman: Am. Jour. Med. Sc., January, 1900

3. Cabot: Boston Med. and Surg. Jour., 1897 .

4. Kerr: Philadelphia Med. Jour., Aug. 25, 1900.

3. Athinson: Philadelphia Med. Jour., June 3, 1900.
Askanazy ${ }^{7}$ found the embryos in the abdominal lymphglands; further studies by Graham $^{8}$ and Staubli ${ }^{9}$ confirm this. Frothingham, ${ }^{10}$ in a recent article, shows that the parasites penetrate the mucous membrane of the large and small intestine. Neither the male nor the female worm penetrates the connective tissue of the villi; the embryos are discharged into the tissues and these gain entrance to the lymph spaces, the adult worms remaining under the mucous coats of the intestinal wall, which probably accounts for the difficulty of finding the worms in the stools, except when looked for very early - that is, in the first two or three days after the infection-a time when symptoms seldom point to any definite infection with this parasite.

While Staubli in 1905 reported the recovery of the embryos from the heart's blood of infected guinea-pigs, it is but recently that Herrick and Janeway ${ }^{11}$ first denonstrated the embryos in the circulating blood of man. By collecting 10 c.c. blood from the arm vein in a 3 per cent. solution of acetic acid, four embryos were seen in one member of a family in which nine were affected with the disease. This is undoubtedly an important advance in our method of diagnosis, and if further observations confirm these findings, blood examinations will have the same value in this disease as in malaria.

1819 Linden Avenue.

\section{THE COMPARATIVE STRENGTH OF DIGIPURATUM}

WORTH HALE

Assistant Pharmacologist, Hygienic Laboratory; U. S. Public Health and Marine-Hospital Service WASHINGTON, D. C.

In another paper $^{1}$ I recently gave a brief outline of certain undesirable effects which frequently make digitalis medication difficult. These have constituted such decided hindrances to the best results where such medication was indicated that a number of investigators and manufacturers have employed many different formulas and pharmaceutic procedures in an effort to get rid, at least, of certain of these disturbing factors.

Among the more recent products of this class is digipuratum (extract of digitalis depuratum, Knoll). The method of preparation is kept secret, but digipuratum is said to be a purified extract of digitalis, which, by a process of purification originated by Gottlieb, ${ }^{2}$ is freed from about 85 per cent. of inert and undesirable material, including the irritating saponin-like body digitonin. The remaining 15 per cent. is said to represent the full activity of the original extract and to contain both digitoxin and digitalin. The digitalis extract having been thus purified, the resulting yellowish solution is mixed with such amounts of milk-sugar that when tested biologically on frogs it has the same activity as a like amount of strongly active digitalis leaves-that is, $1 \mathrm{gm}$. digipuratum equals in activity $1 \mathrm{gm}$. powdered digitalis leaves.

Digipuratum is further said to be insoluble in cold water and in acids, but to be easily soluble in weak alkalies. Theoretically, therefore, it is said to have no action

7. Askanazy : Virchow's Arch. f. path. Anat., 1895, cxli, 42

8. Graham : Arcb. f. mikr. Anat., 1897. i, 219.

9. Staubli: Deutsch. Arch. f. klin. Med., Ixxxv, 286.

10. Frothingham, C.: Intestinal Lesions Caused by Trichinella Spiralis in Rats, Arch. Int. Med., January, 1909, ii, 505.

11. Herrick, W. W., and Janeway, T. C.: Arch. Int. Med., April 1909, iii, 263 .

1. Hale, W.: A Comparative Study of Digalen, THe Journat A. M. A.. Jan. 1, 1910

2. Hoepffner: München. med. Wchnschr., 1908, Iv, 1774 